\title{
Endocrine Responses of Type 1 (Insulin-Dependent) Diabetic Patients Following Successful Pancreas Transplantation
}

\author{
G. Pozza ${ }^{1}$, J. Traeger ${ }^{2}$, J. M. Dubernard ${ }^{3}$, A. Secchi ${ }^{1}$, A. E. Pontiroli ${ }^{1}$, E. Bosi' ${ }^{1}$, M. C. Malik ${ }^{2}$, A. Ruitton ${ }^{4}$ and N. Blanc ${ }^{2}$ \\ ${ }^{1}$ Clinica Medica VIII, University of Milan, S. Raffaele Hospital, Milan, Italy, ${ }^{2}$ Clinique de Nephrologie et des Maladies Metaboliques and \\ ${ }^{3}$ Service d'Urologie, E. Herriot Hospital, INSERM U 80, and ${ }^{4}$ INSERM U 34, Debrousse Hospital, Lyon, France
}

\begin{abstract}
Summary. The aim of the present study was to evaluate the insulin and glucagon responses to various stimuli in patients following pancreatic transplantation. Four Type 1 (insulin-dependent) diabetic patients with end-stage renal failure who had received a cadaveric segmental, neoprene-injected, pancreas transplant, in association with kidney transplantation, were investigated. Free-insulin, pancreatic glucagon, and growth hormone concentrations were measured after both oral and intravenous glucose tolerance tests, and following tolbutamide, arginine and arginine plus somatostatin infusions. Tests were performed 1 month (three cases) and 30 months (one case) after surgery, when no insulin administration was required. Four non-diabetic kidney grafted patients, matched for duration of graft survival and immunosup-
\end{abstract}

pressive treatment (steroids, azathioprine and anti-lymphocyte-globulins), served as control subjects. Impaired glucose tolerance was present in all diabetic and control patients. This was possibly related to immunosuppressive treatment. In comparison with control subjects, insulin release was normal in response to arginine and tolbutamide but was reduced in response to oral and intravenous glucose, while glucagon and growth hormone release were similar in both groups. Somatostatin was less effective in diabetic patients than in control subjects in suppressing insulin and glucagon release.

Key words: Type 1 diabetes, pancreas transplantation, pancreas, insulin, glucagon, growth hormone, kidney transplantation, somatostatin (cyclic).
Pancreas transplantation is intended to restore endogenous insulin secretion and to normalize metabolism in patients suffering from Type 1 (insulin-dependent) diabetes mellitus [1]. Pancreatic transplantation in a diabetic patient who is a candidate for kidney transplantation, because of end-stage renal failure, does not constitute an undue added risk. For this reason, pancreas transplantation has usually been performed together with kidney transplantation at the E. Herriot Hospital in Lyon. Details of the surgical procedure have been presented elsewhere [2]. When the surgical procedure is successful, there is a dramatic improvement in the diabetes, so that insulin treatment is no longer needed. Restored insulin secretion is also evident [3-6]. The aim of our study was to evaluate the insulin and glucagon response to provocative stimuli in such patients. This is of importance as the grafted pancreas is heterotopic, is away from the usual neuro-humoral environment, and secretes into the general circulation instead of the portal system.

\section{Patients and Methods}

\section{Patients}

Four Type 1 diabetic patients, who had undergone kidney and pancreas transplantation apparently successfully, were investigated. Clinical data are shown in Table 1. Segmental pancreas transplantation was performed according to our technique [2]. Briefly, a segment of the pancreas (body and tail), injected intraductally with neoprene in order to suppress exocrine function, was vascularized by anastomosis to iliac artery and vein.

During the period of investigation, all the patients had been insulin-independent since transplantation. Immunosuppressive treatment was based on multiple blood transfusions or thoracic duct drainage and on administration of prednisolone $(10-20 \mathrm{mg} /$ day $)$, azathioprine $(0-100 \mathrm{mg} /$ day) and equine anti-lymphocyte-globulins $(8 \mathrm{mg}$. $\mathrm{kg}^{-1} \cdot \mathrm{day}^{-1}$ ) [7]. No major renal rejection episodes occurred in three diabetic patients (Nos. 1, 2, 4), but in the fourth patient, three episodes of rejection occurred (on days 70,130 and 230). These episodes were treated with massive doses of prednisolone $\left(4 \mathrm{mg} \cdot \mathrm{kg}^{-1} \cdot \mathrm{day}^{-1}\right.$ for 2 days), and a condition of subclinical chronic renal rejection followed. As a control group, four non-diabetic kidney grafted patients (Nos. $5,6,7,8)$ were subjected to the same studies. Clinical data are 


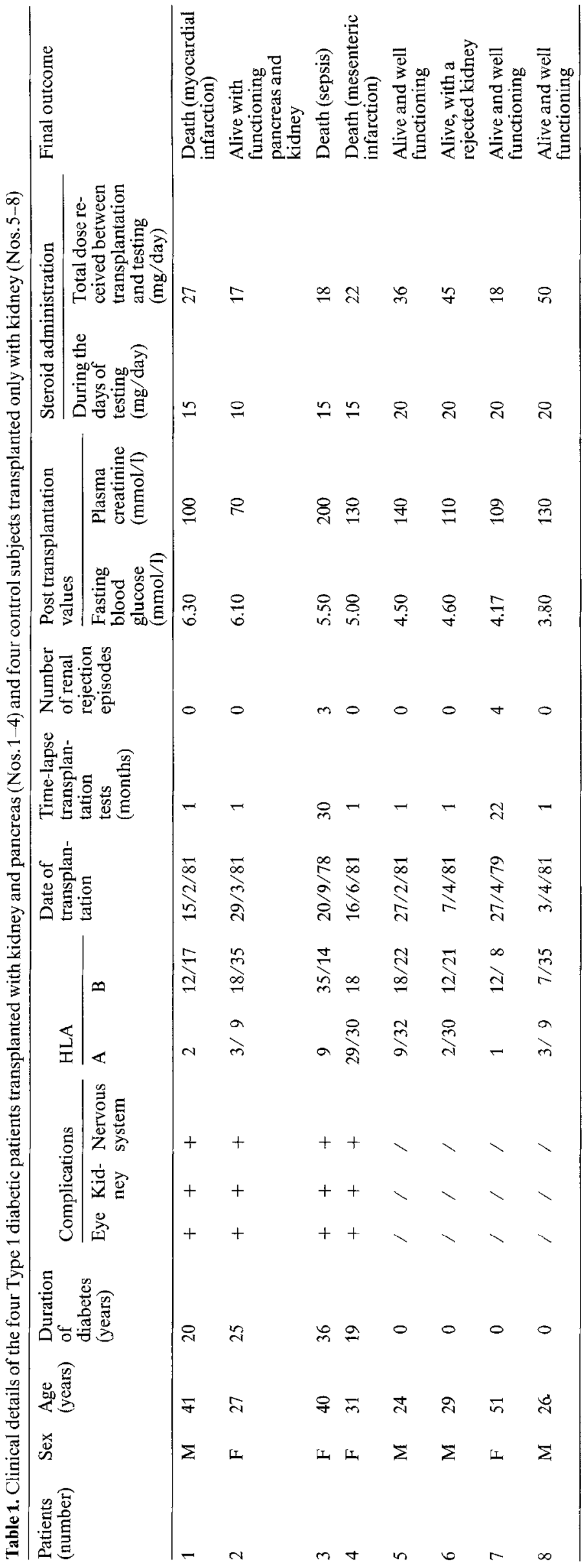

shown in Table 1. Due to the small number of diabetic patients and to the different time-lapse from transplantation, the control subjects were selected to be matched for immunosuppressive treatment and duration of grafting. The matching of the patients is as follows: 1 versus 5,2 versus 6,3 versus 7,4 versus 8 .

\section{Test Procedures}

The diabetic and control patients were subjected to the following tests: an oral glucose tolerance test $(75 \mathrm{~g}$ glucose with samples at 0,15 , $30,45,60,90,120,180 \mathrm{~min})$; an intravenous glucose tolerance test $(0.5 \mathrm{~g}$ glucose $/ \mathrm{kg}$ body weight with samples at $0,5,10,20,30,40,60$, $90 \mathrm{~min}$ ); a tolbutamide infusion ( $1 \mathrm{~g}$ IV with samples at $0,3,5,10,20$, $30,40,60 \mathrm{~min})$; an arginine infusion ( $25 \mathrm{~g}$, IV, as a $10 \%$ solution given over $30 \mathrm{~min}$ with samples at $0,5,10,20,30,45,60,90,120 \mathrm{~min}$ ) and an arginine plus cyclic somatostatin infusion (Clin-Midy, Montpellier, France) $(250 \mu \mathrm{g}$ bolus IV at time $0 \mathrm{~min}$ and $250 \mu \mathrm{g}$ IV infusion over $120 \mathrm{~min}$, samples as in the arginine test). These tests were performed in the recumbent position at $09.00 \mathrm{~h}$ after an overnight fast. Not all patients were submitted to all tests. Informed consent was obtained from all diabetic and control patients before testing.

\section{Assays}

Blood samples were obtained at the time intervals indicated in the test procedures, by means of an indwelling catheter inserted into a forearm vein or into the subclavian vein and kept patent by a slow saline infusion $(0.154 \mathrm{~mol} / \mathrm{l})$. Blood was placed into tubes containing disodium EDTA and aprotinine $(10,000 \mathrm{KIU} / \mathrm{ml})$ and centrifuged at $4{ }^{\circ} \mathrm{C}$. Blood glucose levels were evaluated by an enzymatic method. Plasma was stored at $-20^{\circ} \mathrm{C}$ until assayed for free-insulin (IRI) $[8,9]$, growth hormone $(\mathrm{GH})[10]$ and immunoreactive glucagon (IRG). IRG was assayed using the antibody R-78 at a working concentration of 1:24000; the antibody was C-terminus directed and therefore reacted only with pancreatic glucagon. Incubation lasted $48 \mathrm{~h}$ at $4^{\circ} \mathrm{C}$; separation of free-from bound-hormone was obtained by precipitation with polyethyleneglycol $20 \%$ and centrifugation at $2000 \times \mathrm{g}$ for $20 \mathrm{~min}$. Free-IRI was assayed according to the method of Nakagawa et al. [8] and Heding [9]. Kits for IRG were supplied by Serono-Immunochemicals, Biodata, Milan, Italy, and kits for free-IRI by Novo, Copenhagen, Denmark. In our laboratory, fasting IRI, IRG and GH levels are $0-20 \mathrm{mU} / 1,50-200 \mathrm{mIU} / 1$ and $0-20 \mathrm{mIU} / 1$, respectively. The inter- and intra-assay variation were, respectively, $13.4 \%$ and $6.4 \%$ for $\mathrm{GH}, 15 \%$ and $9 \%$ for IRG, $11 \%$ and $10 \%$ for IRI.

\section{Results}

According to the criteria of the WHO Committee [11], oral glucose tolerance testing revealed an impaired glucose tolerance in all control subjects. In our diabetic patients, glucose tolerance was normal in one case, impaired in one case and diabetic in two cases, although fasting blood glucose levels were either normal or only slightly above the normal range (range $4.72-8.05 \mathrm{mmol} / 1)$. The IRI response to the same test was more pronounced in the control subjects than in the diabetic patients, and in particular in the two diabetic patients who had a diabetic response to the oral glucose tolerance test. IRG and GH levels during the same test were not different in the diabetic and control patients, and did not change significantly. Blood glucose levels during the IV glucose tolerance test were normal in the control subjects (Conard's K [12] being 1.75, 1.27, 2.1, 

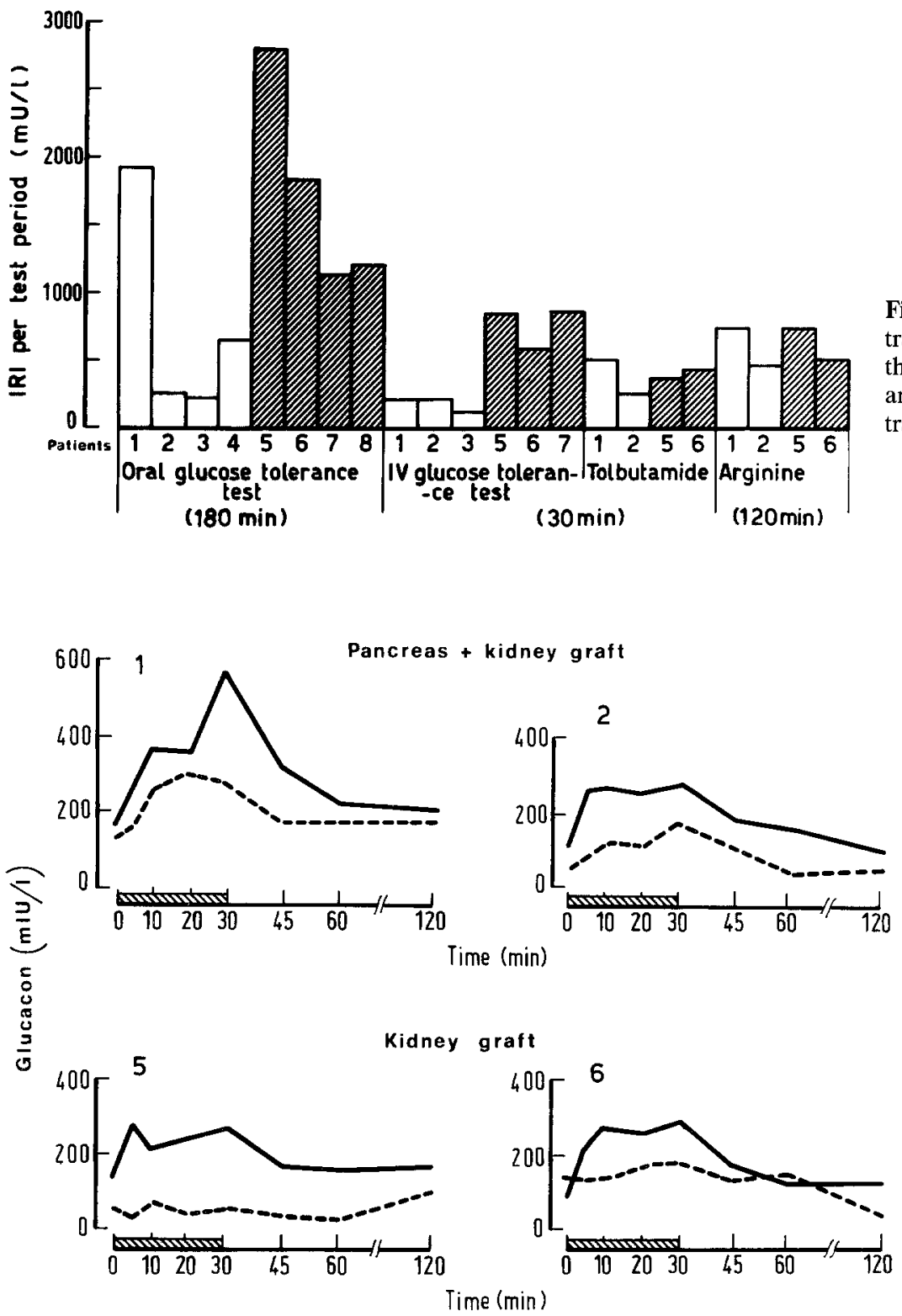

Fig. 1. Insulin secretory areas (IRI) (calculated by the trapezoidal method) after different insulinogenic stimuli in the Type 1 diabetic patients transplanted with pancreas and kidney ( $\square$; Nos.1-4) and in non-diabetic patients transplanted only with kidney ( $ஐ$; Nos.5-8) respectively); whereas in the diabetic patients, one normal response $(K=1.32)$, one borderline response $(\mathrm{K}=0.90)$ and one diabetic response $(\mathrm{K}=0.55)$ were observed. The IRI response to IV glucose was normal in the control subjects, with the presence of a peak level at $5 \mathrm{~min}$, but was reduced in the diabetic patients, with an absence of an early secretory peak. On the other hand, the tolbutamide test revealed no difference between the two groups; IRI release reached a peak value (range $34-70 \mathrm{mU} / 1$ ) between 3 and $5 \mathrm{~min}$ in both groups. Arginine-induced IRI release was biphasic and similar in the two groups. Figure 1 shows the net IRI secretory areas (calculated by the trapezoidal method) in response to various stimuli in both groups. It is evident that striking differences were observed only in the IRI response to both oral and intravenous glucose, but not to arginine or tolbutamide. IRG (Fig. 2) and GH (Fig. 3) responses to arginine were also similar in the two groups. When somatostatin was infused with arginine, suppression of IRI and IRG was complete in the control subjects but only partial in the diabetic patients. The effect of somatostatin on arginine-induced GH release did not vary between the groups (Fig. 3).

\section{Discussion}

Pancreatic transplantation is performed in Type 1 diabetic patients in order to provide self-regulating insulin release and to revert metabolism to normal. From the various surgical procedures which have been proposed by several authors including ourselves [1], we now choose to perform segmental transplantation [2]. In this study, we present data concerning insulin and glucagon release in four such patients in whom the diabetic state was replaced by apparently normal glucose homeosta- 


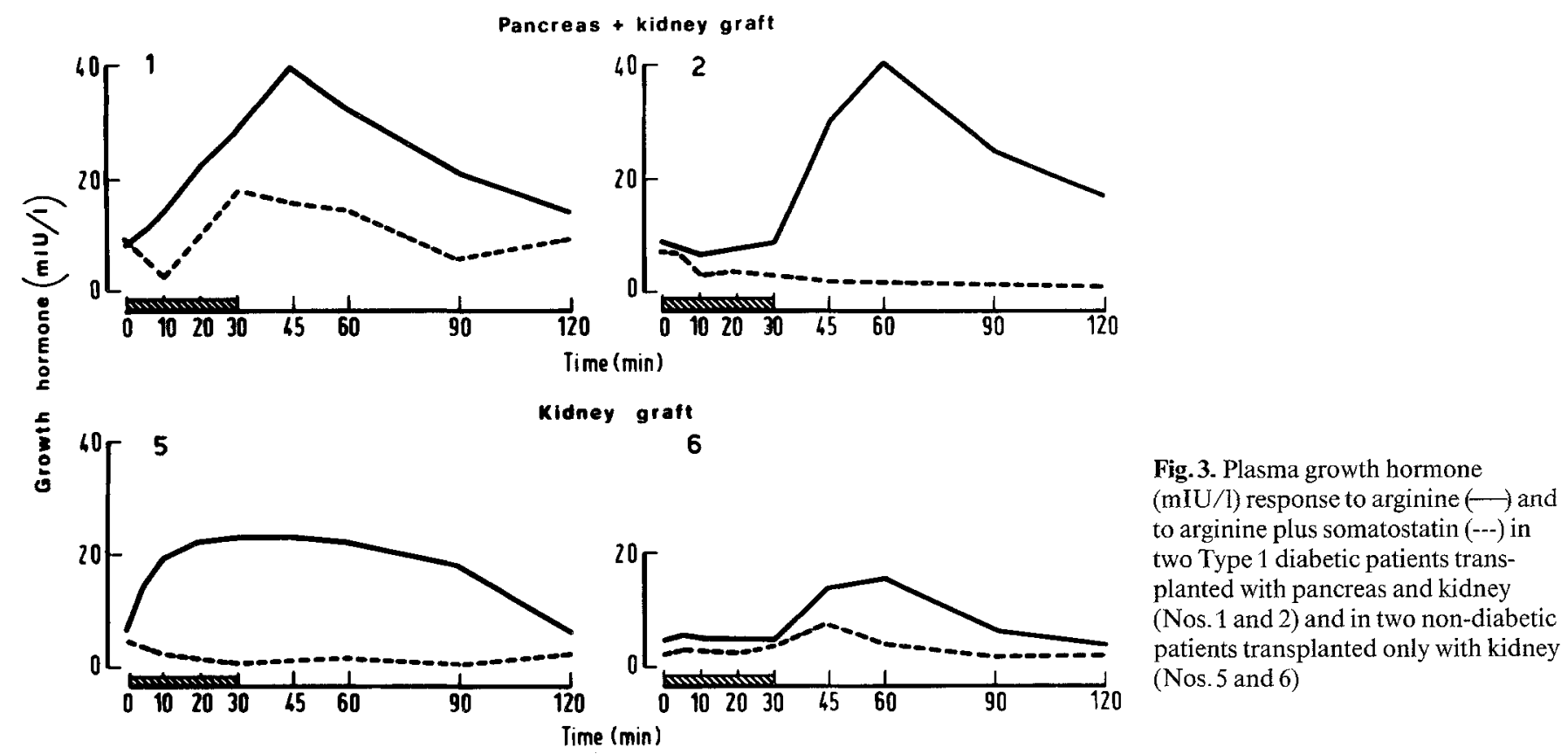

sis. No comparison was attempted between pre- and post-surgery condition in these pancreas-grafted patients because of absolute insulin-dependence and because of the concomitant uraemic state.

The number of patients studied is not large enough to draw general conclusions. However glucose tolerance was impaired, although fasting blood glucose levels were normal or only slightly above normal levels. In all the diabetic patients (except No. 4, who had a normal glucose tolerance test), the peak IRI level was reached between 90 and $120 \mathrm{~min}$, that is delayed if compared with normal subjects but similar to that usually seen in patients with impaired glucose tolerance. Several factors might be responsible for the reduced insulin secretion observed in the diabetic patients. Firstly, only a part of the pancreas was transplanted, secondly, undetected pancreatic rejection might be present and finally a period of warm ischaemia is inevitable during surgical procedures, possibly leading to necrosis and permanent damage of the endocrine tissue. In addition, occlusion of the pancreatic duct and suppression of exocrine function may be involved, since in the experimental animal duct ligature leads to impaired glucose tolerance and reduced IRI release [13]. Furthermore, long-term fibrosis of the exocrine pancreas leads to a reduced insulin content in the experimental animal. The transplanted pancreas is also far from its original location and gastrointestinal hormones are known to stimulate IRI and IRG release in the experimental animal $[14,15]$. The reduced IRI response to oral glucose might be explained on this basis only if evidence is obtained that the transplanted pancreas is less sensitive to gastrointestinal hormones. The transplanted pancreas is also denervated, and lack of the known stimulatory role played by the vagus nerve [16] and by acetylcholine [17] might also account for the decreased insulin response to glucose. In man, however, the effect of surgical procedures, such as vagotomy, on insulin release is not completely understood [18]. At present the different IRI responses to glucose and to other stimuli, such as tolbutamide and arginine, could be because these stimuli have different mechanisms of action in eliciting IRI release [19].

Glucagon response to glucose and arginine was similar in the two groups of subjects: fasting IRG levels were within the normal range and IRG release was inhibited or unaffected by glucose, and stimulated by arginine. These data indicate that the transplanted A cell responds normally to classical stimuli. In addition, plasma IRG levels were not abnormally elevated, as is usually seen in poorly controlled diabetes [20]. Also GH release, which is known to be exaggerated in poorly controlled diabetes [20], was normal in our patients.

Somatostatin seemed to be more effective in inhibiting IRI and IRG release in the control subjects than in the diabetic patients. No explanation is available for this difference. It is known that somatostatin is able to inhibit IRI and IRG release from the perfused pancreas in situ, but not from isolated perfused islets [21]. Hypersomatostatinaemia has been described repeatedly in experimentally-induced diabetes in animals and is reversed by pancreatic transplantation in rats [22]. Although plasma somatostatin levels were not evaluated in our patients, somatostatin was equally active in both groups in suppressing $\mathrm{GH}$ release.

Currently uraemia represents the major cause of death in diabetic patients [23]. Chronic haemodialysis is unsatisfactory because mortality is almost double that of non-diabetic patients undergoing haemodialysis [23]. Therefore kidney transplantation represents the treatment of choice for such patients. In experienced hands 
the addition of segmental pancreatic transplantation to kidney transplantation does not seem to increase the overall surgical risk, and can be considered a further step in the treatment of these patients, aiming at a complete cure not only of uraemia, but also of Type 1 diabetes itself.

Acknowledgments. This work was in part supported by a CNR grant, No CT 81.00320.04(115.10394).

\section{References}

1. Sutherland DER (1981) Pancreas and islets transplantation. II, Clinical Trials. Diabetologia 20:435-450

2. Dubernard JM, Traeger J, Neyra P, Touraine JL, Tranchant D, Blanc Brunat $N(1978)$ New method of preparation of a segmental pancreatic graft for transplantation. Trials in dogs and in man. Surgery 84: 633-639

3. Sutherland DER, Goetz FC, Najarian JS (1980) Report of twelve clinical cases of segmental pancreas transplantation at the University of Minnesota. Transplant Proc 12: 33-39

4. Traeger J, Dubernard JM, Ruitton AM, Malik MC, Touraine JL (1980) Clinical experience with 15 neoprene injected pancreatic allotransplants. Transplant Proc 12:44-50

5. Ostman J, Arner P, Groth GC, Gunnarson R, Heding L, Lundgren $G$ (1980) Plasma C-peptide and serum insulin antibodies in diabetic patients receiving pancreas transplant. Diabetologia 19: $25-30$

6. Sutherland DER, Najarian JS, Greensberg BZ, Senske BJ, Anderson GE, Francis RS, Goetz FC (1981) Hormonal and metabolic effects of a pancreatic endocrine graft. Ann Int Med 95: 537-541

7. Touraine JL, Betuel H, Malik MC, Dubernard JM, Traeger J (1980) Immunologic preparation of the pancreatic transplant recipient. Transplant Proc 12: 11-14

8. Nakagawa S, Nakayama $H$, Sasaki T, Yoshino K, Ying Yu Y, Shinozaki K, Aoki S, Mashimo K (1973) A simple method for the determination of serum free insulin levels in insulin-treated patients. Diabetes 22: 590-600

9. Heding LG (1972) Determination of total serum insulin in insulin treated diabetic patients. Diabetologia 8:260-266

10. Desbuquois B, Aurbach GD (1971) Use of polyethylene glycol to separate free and antibody bound peptide hormones in radioimmunoassay. J Clin Endocr 33: 732-738
11. WHO Expert Committee on Diabetes Mellitus (1980) World Health Organisation, Geneva, pp 9-12

12. Conard V (1955) Mesure de l'assimilation du glucose: bases theoriques et application cliniques. Acta Medica Belgica 10: $148-155$

13. Heptner W, Neubauer HP, Schleyerbach R (1974) Glucose tolerance and insulin secretion in rabbits and dogs after ligation of the pancreatic duct. Diabetologia 10: 193-196

14. Creutzfeldt W (1979) The incretin concept today. Diabetologia 16: $75-85$

15. Unger RH, Eisentraut AM (1969) Entero-insular axis. Arch Intern Med 123:261-266

16. Bloom SR, Vaughan NJA, Russel RCG (1974) Vagal control of glucagon release in man. Lancet 2:546-549

17. Katinuma H, Kaneto A, Kuzuya T, Nakao K (1968) Effects of methacholine on insulin secretion in man. $J$ Clin Endocrinol Metab 28: 1384-1388

18. Lund B, Aagaard P, Deckert T (1975) Effect of vagothomy on insulin release after oral and intra-venous glucose administration. Scand J Gastroent 10:777-780

19. Gerich JE, Charles MA, Grodsky GM (1974) Characterization of the effects of arginine and glucose on glucagon and insulin release from the perfused rat pancreas. J Clin Invest 54: 833-841

20. Hansen AP, Johansen K (1970) Diurnal pattern of blood glucose, serum FFA, insulin, glucagon and growth hormone in normals and juvenile diabetics. Diabetologia 6:27-33

21. Norfleet WT, Pagliara AS, Haymond MV, Matschinsky F (1975) Comparison of alpha and beta cell secretory responses in islets isolated with collagenase and in the isolated perfused pancreas of rats. Diabetes 24:961-970

22. Chiba T, Taminato T, Kadowaki S, Chihara K, Matsukura S, Nozawa N, Seino Y, Fujita T (1981) Reverseal of increased gastric somatostatin in streptozotocin-diabetic rats by whole pancreas transplantation. Diabetes 30: 724-727

23. Najarian JS, Sutherland DER, Simmons RL, Howard RJ, Kjellstrand CM, Ramsay RC, Goetz FC, Fryd DS, Sommer BG (1979) Ten years experience with renal transplantation in juvenile onset diabetics. Ann Surg 190: 487-500

Received: 1 April 1982

and in revised form: 18 November 1982

Professor G. Pozza

Clinica Medica VIII

Ospedale San Raffaele

Via Olgettina, 60

20132 Milan, Italy 